\title{
Dominance of Microcystis with Special Reference to Carbon Availability in Lake Water
}

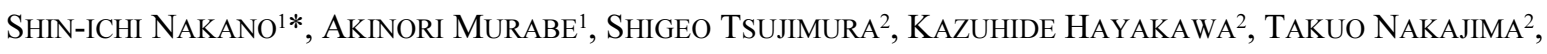 \\ MiCHIO KUMAGAI ${ }^{2}$, CHUNMENG JIAO ${ }^{2}$ and ZEN'ICHIRO KAWABATA ${ }^{3}$ \\ ${ }^{1}$ Center for Marine Environmental Studies, Ehime University, 3 Bunkyo-cho, Matsuyama 790-8577, Ehime, \\ Japan \\ ${ }^{2}$ Lake Biwa Research Institute, 1-10 Uchidehama, Otsu 520, Shiga, Japan \\ ${ }^{3}$ Center for Ecological Research, Kyoto University, Kamitanakami Hirano-cho 509-3, Otsu 520-2113, Shiga, \\ Japan
}

(Received July 22, 2002-Accepted December 25, 2002)

The mechanism of dominance by Microcystis spp. (Cyanophyceae) was examined with special reference to the concentration of dissolved inorganic carbon (DIC), in in situ experiments using lake water. Lake water collected from mesotrophic Lake Biwa was enriched with nitrogen and phosphorus nutrients prior to the experiments, and use of a $\mathrm{NaHCO}_{3}-\mathrm{Na}_{2} \mathrm{CO}_{3}$ buffer was successful in allowing a change of DIC concentrations for phytoplankton without lowering the $\mathrm{pH}$. The experiments consisted of a control (no DIC addition) and a treatment. There were no significant differences in levels or patterns of change in $\mathrm{pH}$ values, nutrient (nitrogen and phosphorus) or chlorophyll concentrations between the two systems. Microcystis became dominant in the control system, while Scenedesmus sp. dominated in the DIC system. This suggested that the low DIC concentration in surrounding water favored dominance by Microcystis although this cyanobacterium needed some other carbon sources in order to proliferate. The buoyancy regulation of Microcystis may be the strategy by which it floats up to the surface layer, where there is abundant $\mathrm{CO}_{2}$, and dominates when the DIC concentration in the water column is low.

Key words: Microcystis, DIC concentration, carbon limitation, Chlorophyceae

Cyanobacterial blooms are a common symptom of lake eutrophication, and numerous studies have examined the mechanisms by which they are initiated. The chemical environment for cyanobacterial dominance has also been investigated intensively. Previous studies have demonstrated that $\mathrm{N}_{2}$-fixing cyanobacteria such as Anabaena are at an advantage under $\mathrm{N}$ limited conditions compared to non $\mathrm{N}_{2}$-fixing phytoplankton, and the cyanobacteria tend to dominate when the N:P ratio in lake water is low ${ }^{13,24)}$. In contrast, the bloom formation mechanisms of Microcystis, the most notorious bloom-forming cyanobacterium, have not yet been fully explained. Although dominance by Microcystis does require plenty of nitrogen and phosphorus ${ }^{24,25)}$, supplement-

\footnotetext{
* Corresponding author; E-mail: shin@agr.ehime-u.ac.jp, Tel and Fax: +81-927-8551
}

ing these nutrients also enhances the growth of other algae such as Chlorophytes ${ }^{24,25)}$. Since Microcystis blooms are a nuisance in many lakes all over the world, it is important to elucidate the mechanisms of their formation.

Another important factor responsible for cyanobacterial blooms is $\mathrm{CO}_{2}$ availability ${ }^{8-12,17-20)}$. $\mathrm{King}^{8,9)}$ hypothesized that cyanobacteria, though superior competitors of low $\mathrm{CO}_{2}$ concentrations compared with other phytoplankters, would predominate after a further reduction in the $\mathrm{CO}_{2}$ concentration. In an experimental system, the dominant phytoplankton shifted from cyanobacteria to chlorophytes after $\mathrm{CO}_{2}$ addition $^{18)}$, and the succession was reversible when the $\mathrm{pH}$ was raised. Klemer and colleagues ${ }^{11,12)}$ examined the role of carbon availability in buoyancy regulation which makes cyanobacteria superior to other phytoplankters in $\mathrm{CO}_{2}$ uptake. Cyanobacteria have a carbon concentrating mechan- 
ism which elevates the $\mathrm{CO}_{2}$ level around the active site of the primary photosynthetic carboxylating enzyme Rubisco, allowing the organisms to conduct efficient photosynthesis and may provide them with an advantage over other phytoplankters $^{1,2)}$.

Although the phytoplankton succession due to addition of $\mathrm{CO}_{2}$ was obvious in Shapiro's study ${ }^{18)}$, the effect was synergistic because in addition to changing the carbon concentration, it changed the $\mathrm{pH}$. Shapiro ${ }^{18)}$ examined phytoplankton succession after addition of $\mathrm{CO}_{2}$ dissolved in an alkaline solution to keep the $\mathrm{pH}$ high and observed the same result as $\mathrm{CO}_{2}$ addition, though his results varied between experiments (Table 1 in Shapiro ${ }^{18)}$ ). Further, most studies which have examined cyanobacterial dominance in relation to carbon concentration, or $\mathrm{pH}$ changes, refer to dominance by $\mathrm{N}_{2}$-fixing species $\left.3,8,12,17,18,20\right)$. The $\mathrm{CO}_{2}$ concentration indirectly affected the dominance of the $\mathrm{N}_{2}$-fixing cyanobacterium Aphanizomenon flos aquae caused by an alteration in $\mathrm{pH}^{3}$. However, the available information about this aspect of non- $\mathrm{N}_{2}$-fixing genera, such as Microcystis, is still limited.

In the present study, we examined dominance by Microcystis with special reference to the carbon concentration in in situ experiments using lake water.

A 160 liter sample of surface water was collected from an enclosure placed in Akanoi Bay of Lake Biwa ${ }^{16)}$ using a bucket, on 17 August 1997. The bay is the most eutrophic area of the lake ${ }^{15,23)}$ and the concentrations of nutrients and conditions of other environmental variables in the enclosed waters are described elsewhere ${ }^{16)}$.

We poured 40 liters into each of four 70 liter polychlorinated vinyl buckets (diameter, ca. $40 \mathrm{~cm}$; depth, ca. $60 \mathrm{~cm}$ ) and added $\mathrm{N}$ and $\mathrm{P}$ nutrients or dissolved inorganic carbon (DIC) as described below. Removal of herbivores was impossible due to serious overlap of sizes between Microcystis colonies and possible herbivores such as planktonic crustaceans and rotifers. Two buckets served as the DIC system, and the other two as the controls. For the DIC system, the concentration of DIC was raised using a $\mathrm{NaHCO}_{3}-\mathrm{Na}_{2} \mathrm{CO}_{3}$ buffer solution which is commonly used in biochemical studies ${ }^{22}$. $\mathrm{NaHCO}_{3}$ and $\mathrm{Na}_{2} \mathrm{CO}_{3}$ solutions both of which had a carbon concentration of $2.4 \mathrm{~g} \mathrm{C}^{-1}$ were prepared, and $44.8 \mathrm{ml}$ of the former and $35.2 \mathrm{ml}$ of the latter solution was added to the DIC system to adjust the $\mathrm{pH}$ at 9.8, which is the same as that of the lake water. The initial DIC concentration in the addition system was $9.2 \mathrm{mg} \mathrm{C}^{-1}$, and that of the control, $4.4 \mathrm{mg} \mathrm{Cl}^{-1}$. $\mathrm{NH}_{4} \mathrm{NO}_{3}$ and $\mathrm{KH}_{2} \mathrm{PO}_{4}$ were added to each bucket at final concentrations of $2000 \mu \mathrm{g} \mathrm{N}^{-1}$ and $100 \mu \mathrm{g} \mathrm{P}$ $1^{-1}$, respectively. The DIC and control systems each consist- ed of buckets containing lake water thus enriched. Hence, solar radiation and water temperature were almost natural except for the absence of sediments. We secured these buckets within the lake enclosure using ropes, incubated them there for 18 days and took subsamples using a ladle from each bucket to monitor water temperature, $\mathrm{pH}$, DIC concentration, chlorophyll concentration, inorganic nitrogen and phosphorus concentrations and phytoplankton cell densities every other day.

Water temperature and $\mathrm{pH}$ were measured using a $\mathrm{pH}$ meter (TOA Co. Ltd., HM-12P). A portion of each water sample was filtered through a Whatman GF/F glass fiber filter. For the filtrate, the DIC concentration was determined using a Total Carbon Analyzer (Shimadzu, TOC-500), concentrations of ammonium $\left(\mathrm{NH}_{4}-\mathrm{N}\right)$, nitrite $\left(\mathrm{NO}_{2}-\mathrm{N}\right)$ and nitrate $\left(\mathrm{NO}_{3}-\mathrm{N}\right)$ nitrogen were determined by the ionchromatographic method (Johnson 19867)), and the dissolved inorganic phosphorus (DIP) concentration was determined by the method of Murphy \& Riley (1962) ${ }^{14)}$.

To determine concentrations of chlorophyll, a 20 to $70 \mathrm{ml}$ portion of each water sample was filtered through a Whatman GF/F filter. Chlorophyll in seston retained on the filter was extracted using $10 \mathrm{ml}$ of acetone:dimethyl sulfoxide $(\mathrm{DMSO})=1: 1$ solution $^{21)}$, and the amount of chlorophyll was determined using a fluorometer (Turner Design Co. Ltd., Model 10-AU-005, Field Fluorometer) ${ }^{4}$. Another 120 to $170 \mathrm{ml}$ portion of the water sample was fixed with acid Lugol's solution at a final concentration of $1 \%$, and the phytoplankton concentrated by natural sedimentation. Phytoplankton cells were enumerated with a haematocytometer under a microscope at $\times 200$ or $\times 400$ magnification. Algal cell numbers were converted into biovolume using the cell volume of each phytoplankter6).

We examined the statistical differences in abundance of dominant phytoplankters, with the Mann-Whitney U-test using StatView ver. 5.0 (SAS Institute Inc.).

A sharp increase in water temperature (Fig. 1A) in the buckets was detected from the first $\left(27.8^{\circ} \mathrm{C}\right)$ to second day $\left(30.2^{\circ} \mathrm{C}\right)$ and thereafter, the temperature gradually decreased. Large fluctuations of $\mathrm{pH}$ were found from the initial day (9.8) to day 4 (ca. 11), and thereafter the $\mathrm{pH}$ generally decreased in both systems (Fig. 1B).

As would be expected, DIC concentrations were higher in the DIC vessels than the controls. Concentrations in both decreased from about day 2 to day 7 (Fig. 1C) after which the control levels stayed fairly constant while the concentration increased slightly in the DIC system, from day 11 onwards. Concentrations of dissolved inorganic nitrogen $\left(\mathrm{DIN}=\mathrm{NH}_{4}+\mathrm{NO}_{2}+\mathrm{NO}_{3}\right.$ ) (Fig. 1D) and phosphorus (DIP) 

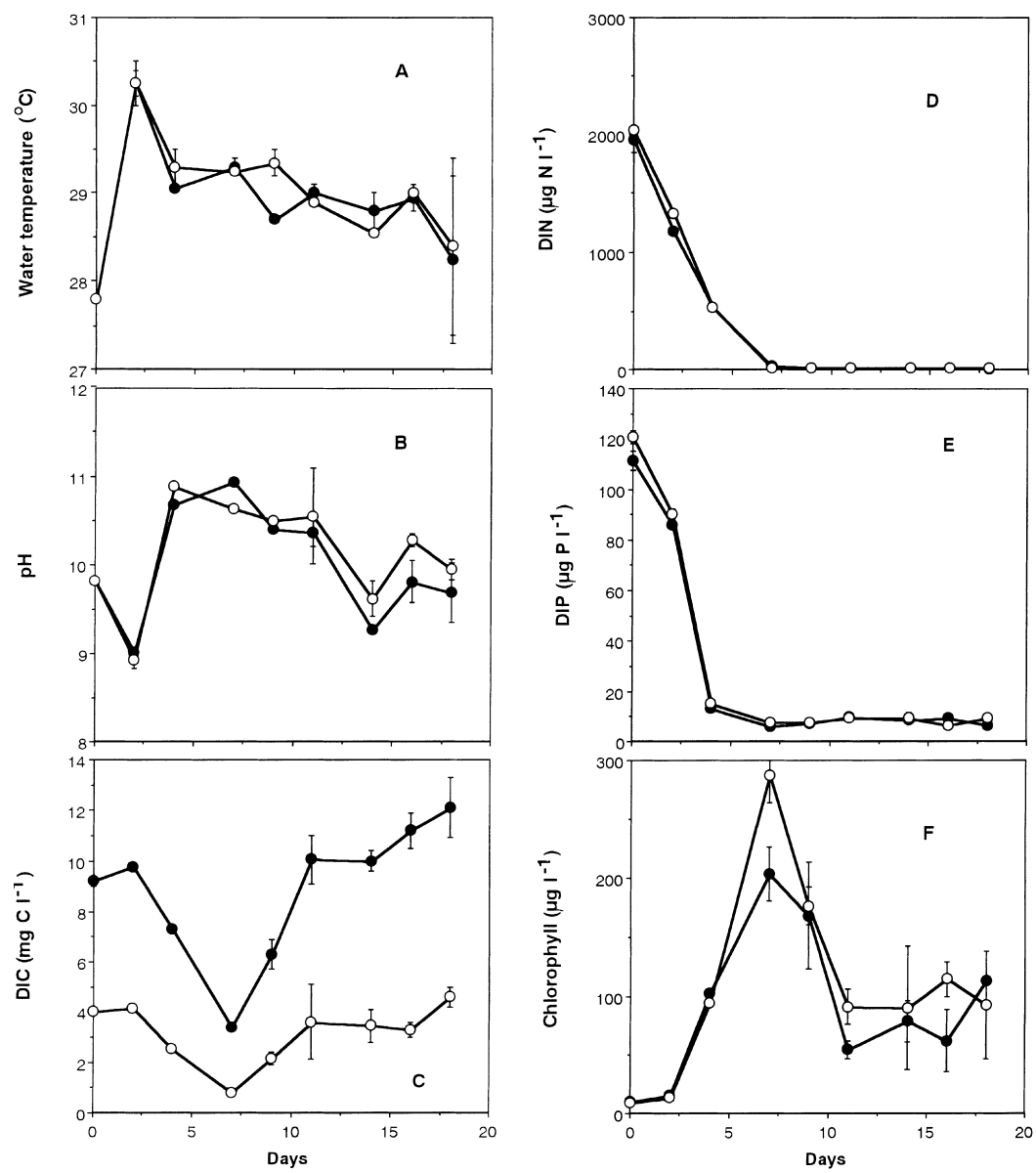

Fig. 1. Changes in water temperature (A), $\mathrm{pH}(\mathrm{B})$, and dissolved inorganic carbon (DIC) (C), dissolved inorganic nitrogen (DIN) (D), dissolved inorganic phosphorus (DIP) (E) and chlorophyll (F) concentrations in the control (open circles) and the DIC (solid circles) systems. Vertical bars which indicate differences between duplicates are shown when they exceed the size of the symbol.

(Fig. 1E) declined sharply in both control and DIC systems from the start of the experiment to day 7 (DIN) and day 4 (DIP), and did not show any significant increase thereafter.

Trends in the change in the chlorophyll concentration in the two systems were also similar (Fig. 1F). The concentration increased rapidly from day 4 to day 7 , decreased from day 9 to day 11 and then fluctuated. Thus, we could find no significant differences in levels or patterns of change in water temperature, $\mathrm{pH}$, nutrient and chlorophyll concentrations between the DIC and control systems, although the maximum concentration of chlorophyll in the former system was higher than that of the control (Fig. 1F).

The dominant phytoplankton species at the start of the experiment were $M$. aeruginosa, Planktosphaeria gelatinosa and Ceratium hirundinella. The species diversity decreased during incubation and, finally, about $95 \%$ of the phytoplankton biomass was Microcystis spp. plus Scenedesmus spp. in both systems (Fig. 2). Hence, Figure 2 shows marked changes in the abundance of these two genera. In the DIC system, they both increased from the start to day 7, but the abundance of Microcystis spp. dominated from day 7 to 11 and remained at low levels from day 14 onwards, while Scenedesmus spp. continued to increase and predominated at the end of the experiment (Fig. 2B). In the control system, the abundance of these two dominant phytoplankters increased, and finally, Microcystis spp. seemed to be more abundant than Scenedesmus spp. despite that the abundances of the two dominant phytoplankton genera were highly variable (Fig. 2A). We examined the differences in abundance between these two dominant phytoplankton genera for day 7 to 11 during Microcystis dominance and day 14 to 18 during Scenedesmus dominance, using the abundances of the two dominant phytoplankton genera and the Mann-Whitney U-test. In both cases, the diffferences were significant at $\mathrm{p}<0.01$ and $\mathrm{p}<0.02$, respectively. For the control system, we also examined the differ- 


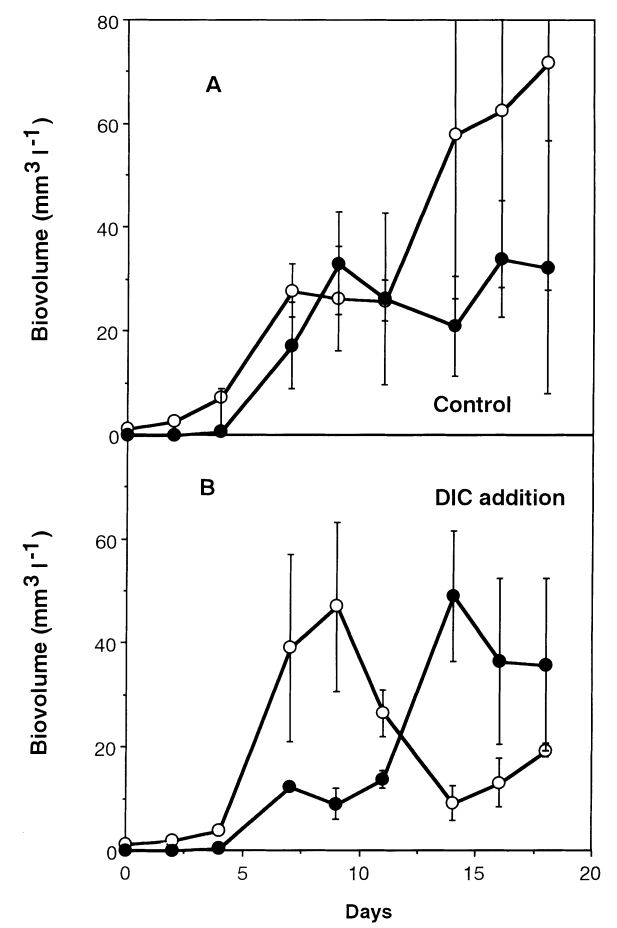

Fig. 2. Changes in biovolume densities of Microcystis spp. (open circles) and Scenedesmus spp. (solid circles) in the control (A) and DIC (B) systems. Vertical bars which indicate differences in biovolume densities between duplicates are shown when they exceed the size of the symbol.

ences in abundance between these two dominant phytoplankton genera from day 14 onwards, and found the difference was not significant ( $\mathrm{p}>0.1)$.

Klemer and colleagues ${ }^{11)}$ examined the effects of changes in carbon availability on the buoyancy of $M$. aeruginosa in chemostat systems, using various $\mathrm{C}: \mathrm{N}$ weight ratios of nutrient supply ranging between 0.54 and 17 . In the present study, C:N ratios at the start of the experiments in the DIC and control systems were respectively 4.5 and 2.0 , suggesting moderate carbon-limitation ${ }^{11)}$. However, the DIC concentrations in both systems increased, after a temporary decrease, and this was due to heterotrophic $\mathrm{CO}_{2}$ release since the increase in DIC concentrations (Fig. 1C) occurred as chlorophyll concentrations decreased (Fig. 1F). Hence, even in the control systems, $\mathrm{CO}_{2}$ might be available to phytoplankton, mainly through heterotrophic activity. Despite this, there were large differences in DIC concentrations between the control and DIC systems (Fig. 1C).

The control system of the present study suggests that low DIC availability in the surrounding water favors Microcystis dominance. In the DIC system, similar results were also obtained on days 7 and 9 when Microcystis grew rapid- ly (Fig. 2B) at low concentrations of DIC (Fig. 1C). The enrichment of lake water using nutrients enhances growth of several phytoplankters ${ }^{18,24,25)}$, and chlorophytes often dominate when carbon is added ${ }^{18)}$. We also detected chlorophyte dominance in the DIC system (Fig. 2B). However, it is still unclear why chlorophytes dominate under carbon-rich conditions. Watanabe \& Miyazaki ${ }^{26)}$ conducted computer simulations of the competition between Microcystis novacekii and Scenedesmus quadricauda in nitrogen limited chemostats, examining two different modes of nutrient supply: small-pulse, high frequency and large-pulse, low frequency. $M$. novacekii outcompeted $S$. quadricauda in the former mode, and $S$. quadricauda became predominant in the latter. In the present study, since the mode of nutrient supply was large-pulse and low frequency, the dominant phytoplankton would not be Microcystis in the control and DIC systems. Indeed, the predominant phytoplankter in the DIC system was Scenedesmus (Fig. 2), as Watanabe \& Miyazaki ${ }^{26)}$ found. However, in contrast to their results, the predominant phytoplankter in our low carbon control system was Microcystis (Fig. 2). In Watanabe \& Miyazaki's ${ }^{26)}$ study, $M$. novacekii and $S$. quadricauda were incubated in a medium with a high $\mathrm{C}: \mathrm{N}$ weight ratio (at least 20.4), indicating high carbon availability for the phytoplankters. In our results, Scenedesmus dominated in the DIC systems where there was plenty of carbon availabile for phytoplankton, suggesting that a high carbon concentration is unfavorable to Microcystis dominance. Thus, our data partly support the results of Watanabe \& Miyazaki ${ }^{26)}$.

Microcystis has the potential for vertical migration using its buoyancy regulation. Thus, it is likely that Microcystis can float up to the surface layer, where there is a high concentration of DIC, and proliferate even under conditions of low DIC availability in the surrounding water. Buoyant cyanobacteria acclimated to high solar irradiance were at an advantage to intercept $\mathrm{CO}_{2}$ diffusing in from the air ${ }^{5}$. Flotation may be the strategy by which Microcystis acquires carbon and dominates when the availability of DIC in the water column is low. In the present incubation, we used buckets where wind probably had less of an effect than in natural lakes. Thus, Microcystis in the present study might also be a superior competitor for $\mathrm{CO}_{2}$ due to flotation.

In Lake Biwa, Microcystis blooms usually occur subsequent to Anabaena blooms ${ }^{15,23)}$. The DIC concentration decreases during Anabaena blooms (Nakano unpublished), suggesting carbon limitation of the phytoplankton, but Anabaena introduces nitrogen through $\mathrm{N}_{2}$-fixation, and the fixed nitrogen may be released in a dissolved form available to other phytoplankton after decomposition of the Anabae- 
na. Thus, the chemical environment after an Anabaena bloom may be favorable to the growth of Microcystis in Lake Biwa.

The initiation of a Microcystis bloom has still not yet been fully explained, although there are numerous studies of this issue. Our results support the hypothesis of $\mathrm{King}^{8,9)}$, the results of Shapiro ${ }^{17,18)}$ and those of Klemer ${ }^{10)}$. Flotation of Microcystis in the surface layer may be advantageous for uptake of DIC, and this enables the cyanobacterium to dominate when concentrations of DIC in the water column are low. High levels of photosynthetic activity of phytoplankton result in low concentrations of DIC, and this is possible in eutrophic waters. Our results shed some light on why $M i$ crocystis dominates in eutrophic waters.

\section{Acknowledgements}

We dedicate the present article to Prof. R. Tsuda who encouraged us throughout the study. We thank J.-J. Frenette, A. Quesada, M. Nakanishi, Masayuki Takahashi, H. Nakahara, Y. Watanabe and K. Okubo for their advice, and M.J. Morris for her collection of English and constructive comments on the earlier version of the manuscript. Thanks are also due to Mikio Takahashi, N. Ochiai and O. Mitamura for chemical analysis, Captain H. Nakayama, K. Nishi, K. Morinaga, L. Ferland and students of Kyoto University, Shiga Prefectural University, Tokyo Metropolitan University, Kinki University, Okayama Science University, Ehime University and Ryukoku University for their help in field work.

\section{References}

1) Aizawa, K. and S. Miyachi. 1986. Carbonic anhydrase and $\mathrm{CO}_{2}$ concentration mechanisms in microalgae and cyanobacteria. FEMS Microb. Rev. 39: 215-233.

2) Badger, M.R., K. Palmqvust and J.W. Yu. 1994. Measurement of $\mathrm{CO}_{2}$ and $\mathrm{HCO}_{3}{ }^{-}$fluxes in cyanobacteria and microalgae during steady-state photosynthesis. Physiol. Plant. 90: 529-536.

3) Caraco, N.F. and R. Miller. 1998. Effects of $\mathrm{CO}_{2}$ on competition between a cyanobacterium and eukaryotic phytoplankton. Can. J. Fish. Aquat. Sci. 55: 54-62.

4) Holm-Hansen, O., C.J. Lorenzen, R.W. Holmes and J.D.H. Strickland. 1965. Fluorometric determination of chlorophyll. J. Cons. Perm. Int. Explor. Mer. 30: 3-15.

5) Ibelings, B.W. and S.C. Marberly. 1998. Photoinhibition and the availability of inorganic carbon restrict photosynthesis by surface blooms of cyanobacteria. Limnol. Oceanogr. 43: 408-419.

6) Ichise, S., T. Wakabayashi, Y. Matsuoka, S. Yamanaka, N. Fujiwara and K. Tanaka. 1995. A simple method for the estimation of phytoplankton biomass based on cell morphology in Lake Biwa. Rep. Shiga Pref. Inst. Pub. Hlth. Environ. Sci. 30: 27-35 (in Japanese).
7) Johnson, E.L. (ed.) 1986. Handbook of ion chromatography. Dionex Corp., Sunnyvale, Calif.

8) King, D.L. 1970. The role of carbon in eutrophication. J. Water Poll. Contr. Fed. 42: 2035-2051.

9) King, D.L. 1972. Carbon limitation in sewage lagoons. In Likens, G.E. (ed.), Nutrients and Eutrophication, ASLO Special Symposia, 1: 98-110, Allen Press, Lawrence, Kansas.

10) Klemer, A.R. 1991. Effects of nutritional status on cyanobacterial buoyancy, blooms, and dominance, with special reference to inorganic carbon. Can. J. Bot. 69: 1133-1138.

11) Klemer, A.R., J.J. Cullen, M.T. Mageau, K.M. Hanson and R.A. Sundell. 1996. Cyanobacterial buoyancy regulation: the paradoxal roles of carbon. J. Phycol. 32: 47-53.

12) Klemer, A.R., L.L. Hendzel, D.L. Findlay, R.A. Hedin, M.T. Mageau and A.E. Konopka. 1995. Carbon availability and the pattern of cyanobacterial dominance in enriched, low-carbon lakes. J. Phycol. 31: 735-744.

13) McQueen, D.J. and D.R.S. Lean. 1987. Influence of water temperature and nitrogen to phosphorus ratios on the dominance of blue-green algae in Lake St. George, Ontario. Can. J. Fish. Aquat. Sci. 44: 598-604.

14) Murphy, J. and P. Riley. 1962. A modified single solution method for the determination of phosphorus in natural waters. Anal. Chim. Acta 27: 31-36.

15) Nakanishi, M., T. Miyajima, S. Nakano and Y. Tezuka. 1992. Studies on the occurrence of Anabaena and Microcystis blooms in Akanoi Bay of the south basin of Lake Biwa, with special attention to nutrient levels. Ann. Rept. Interdiscipl. Res. Inst. Environ. Sci. 11: 67-75.

16) Nakano, S., K. Hayakawa, J.-J. Frenette, T. Nakajima, C. Jiao, S. Tsujimura and M. Kumagai. 2001. Cyanobacterial blooms in a shallow lake: a large-scale enclosure assay of the importance of diurnal stratification. Arch. Hydrobiol. 150: 491-509.

17) Shapiro, J. 1973. Blue-green algae: why they become dominant. Science 179: 382-384.

18) Shapiro, J. 1984. Blue-green dominance in lakes: the role and management significance of $\mathrm{pH}$ and $\mathrm{CO}_{2}$. Internat. Rev. Ges. Hydrobiol. 69: 765-780.

19) Shapiro, J. 1990. Current beliefs regarding dominance by bluegreens: the case for the importance of $\mathrm{CO}_{2}$ and $\mathrm{pH}$. Verh. Internat. Verein. Limnol. 24: 38-54.

20) Shapiro, J. 1997. The role of carbon dioxide in the initiation and maintenance of blue-green dominance in lakes. Freshwat. Biol. 37: $307-323$

21) Shoaf, W.T. and B.W. Lium. 1976. Improved extraction of chlorophyll $\mathrm{a}$ and $\mathrm{b}$ from algae using dimethyl sulfoxide. Limnol. Oceanogr. 21: 343-346.

22) Stoll, V.S. and J.S. Blanchard. 1990. Buffers: Principles and practice. In Deutscher, M.P. (ed.), Methods in Enzumology, Guide to Protein Purification, 182: 24-37.

23) Tezuka, Y. and M. Nakanishi. 1991. Relationship between water quality and phytoplankton in Lake Biwa. Ann. Rept. Interdiscipl. Res. Inst. Environ. Sci. 10: 43-57.

24) Tezuka, Y. and S. Nakano. 1993. Induction of Anabaena bloom by nutrient enrichment to the lake water collected from the south basin of Lake Biwa. Jpn. J. Limnol. 54: 85-90.

25) Vincent, W.F. 1989. Cyanobacterial growth and dominance in two eutrophic lakes: review and synthesis. Arch. Hydrobiol. Beih. Ergebn. Limnol. 32: 239-254.

26) Watanabe, T. and T. Miyazaki. 1996. Maximum ammonium uptake rates of Scenedesmus quadricauda (Chlorophyta) and Microcystis novacekii (Cyanobacteria) grown under nitrogen limitation and implications for competition. J. Phycol. 32: 243-249. 